\title{
The production of official statistics needs to be a separate branch of government
}

\author{
Andreas V. Georgiou ${ }^{\mathrm{a}, \mathrm{b}, \mathrm{c}}$ \\ ${ }^{a}$ Visiting Lecturer (2017), Amherst College, USA \\ ${ }^{\mathrm{b}}$ Consultant - Official Statistics \\ ${ }^{\mathrm{c}}$ Former President (2010-2015), Hellenic Statistical Authority, Greece \\ E-mail:avgeorgiou@yahoo.com
}

\begin{abstract}
The production of official statistics should not be carried out by one of the branches of government whose performance is being assessed on the basis of these statistics. Given that official statistics are tasked with providing the branches of government and the public with the information that enables checking on the performance of various parts of government, the optimal institutional setup for statistical production has to avoid conflict of interest. To do so and to fully and sustainably meet the standard of professional independence, the production of statistics should not be part of the executive branch of government, i.e., it should have institutional independence. The paper presents behaviors and practices consistent with professional independence and discusses the capacity to implement them given the modalities of dependence when statistics production is part of the executive, taking into account safeguards. It concludes that significant risks remain for abuse of the currently existing dependencies of statistics production on the executive and the distinct possibility persists for external pressure or self-censorship, while trust in statistics is not maximized. The paper outlines elements of the needed paradigm shift of institutional independence for official statistics and discusses the costs and benefits of such a shift.
\end{abstract}

Keywords: Official statistics, professional independence, institutional independence, institutional framework

\section{Introduction}

There is no more important issue in official statistics than professional independence, impartiality and objectivity in their production and thus the issue of the conditions of existence of these practices needs to be sustainably addressed. One of the fundamental conditions for the sustainable and robust existence of professional independence, impartiality and objectivity in official statistics is the proper place of official statistics production within government and specifically the institutional independence of statistics. The status quo of official statistics being produced within the executive branch of government is inherently not appropriate and should be changed, with the production of official statistics becoming a separate part of government.

The issue should be of interest to both official statisticians and users of official statistics, whether policy makers, market participants, academic researchers or citizens, irrespective of the part of the world or the country they are concerned with. This is because official statistics is one of the foundation stones of rational and effective policy making, of efficient and welfare maximizing markets, and of functioning democracy and representative government. The issue has important implications for appropriate changes in institutional/legal frameworks affecting the governance of states.

The current paper is organized as follows: Section 2 presents the basic argument for the institutional independence of official statistics. Section 3 discusses the behaviors and practices consistent with professional independence, impartiality and objectivity in the production of official statistics, and how they are not likely to be sustainably implemented - notwithstanding recommended safeguards - in the context of institutional dependence, the modalities of which the paper explores. Section 4 presents an outline of some elements 
of the paradigm of official statistics as institutionally independent, i.e., as a separate branch of government. Section 5 discusses the relative benefits and costs of retaining the production of official statistics within the executive and of rendering such production an independent branch of government and concludes that institutional independence would be appropriate. Section 6 summarizes some conclusions.

\section{The basic argument for the institutional independence of official statistics}

The separation of powers doctrine of Montesquieu aims to ensure that there are checks and balances in the governing of states [1]. Official statistics involves the production of the information by means of which the various branches of government carry out their functions effectively and these checks and balances are operational. Official statistics also make information accessible to the public, which inter alia allows citizens to assess the impact of policies, thus improving accountability of the branches of government for their performance. Official statistics are therefore a fundamental tool for citizens to exercise democratic control of government. It would not be disproportionate to argue that democracy/representative government in the context of a large modern state of millions of citizens cannot function without official statistics.

A basic consequence of the above argument is the following: As official statistics are tasked with providing the various branches of government and the citizenry with the information that enables the control of various parts of government, it is necessary that the production of this critical information does not get carried out by one of the branches of government that is being checked on the basis of this information, thus avoiding the evident conflict of interest. Specifically, in order to fully and sustainably meet the standards of professional independence, impartiality and objectivity of producers of official statistics, the production of such statistics should not be part of the executive branch of government - or any other branch of government - but a separate branch. This institutional independence is what would make the production of official statistics truly independent in a sustainable manner. Paraphrasing Montesquieu's statement in 1748 on the independence of the judiciary, ${ }^{1}$ we argue that the

\footnotetext{
1"The independence of the judiciary has to be real, and not apparent merely" [2].
}

independence of official statistics has to be real and not apparent merely.

Both the real independence of the judiciary ${ }^{2}$ and the real independence of official statistics are essential for the proper governance and functioning of the modern state, society and markets. However, the independence of statistics has only in recent years began to be discussed as important, and largely without drawing the full implications regarding the proper conditions for its existence. In a way the discussion on the requisite independence of official statistics is still in the equivalent of the $18^{\text {th }}$ centrury. Independence of the judiciary has advanced much more.

The issue of institutional independence of official statistics production as a distinct concept from that of professional independence of official statisticians is fundamental. The distinction is akin to the distinction between institutional independence and decisional independence in the case of the judiciary. ${ }^{3}$ Institutional independence of official statistics production is when the latter is independent from the executive, legislative or judicial branches of government. Professional independence is when official statisticians (i) have the sole responsibility for deciding on statistical methods, standards and procedures, and on the content and timing of statistical releases; (ii) have responsibility for ensuring that statistics are developed, produced and disseminated in an independent manner; (iii) are free from political and other external interference in developing, producing and disseminating statistics; and (iv) their compilation of statistics is solely based on statistical principles and statistical legislation in force, without letting any other concerns, including fear or favor, sway their statistical decisions. ${ }^{4}$

\footnotetext{
2 "Judicial independence is the concept that the judiciary needs to be kept away from the other branches of government. That is, courts should not be subject to improper influence from the other branches of government, or from private or partisan interests" [3].

3“"There are two types of judicial independence: institutional independence and decisional independence. Institutional independence means the judicial branch is independent from the executive and legislative branches. Decisional independence is the idea that judges should be able to decide cases solely based on the law and facts, without letting the media, politics or other concerns sway their decisions, and without fearing penalty in their careers for their decisions" [3]

${ }^{4}$ The definition of professional independence of official statistics offered here is informed inter alia by formulations of professionally independent behavior found in the European Statistics Code of Practice [4] and in the International Statistical Institute Declaration on Professional Ethics [5].
} 
As the judiciary's institutional independence is a fundamental condition for its decisional independence, ${ }^{5}$ so the institutional independence of official statistics production is a fundamental condition of existence of sustainable professional independence, impartiality and objectivity in this production. If only professional independence is emphasized for official statistics, this is akin to emphasizing only decisional independence for the judiciary. Obviously it does not work in the case of the judiciary. Why should it work in the case of statistics?

Some may argue that official statistics are there essentially to serve the needs of the state/government, as the name of statistics seems to imply. ${ }^{6}$ However, we would argue that this is an outdated notion; even one fraught with significant risks. The government/state is not anymore the sole or even predominant user of official statistics. Official statistics have evolved from serving the Leviathan (the overwhelmingly powerful government/state) and are actually serving the entire society, in a very wide spectrum of its political, social and economic processes, including in controlling and checking on the Leviathan. ${ }^{7}$ As noted above, official statistics is one of the foundation stones for the functioning of representative government/democracy, markets and scientific research. How can those engaging in these processes in modern society be maximally trustful of official statistics when a major object of their checking, evaluation or study - the executive and its policy outcomes - is at the same time the one that provides the information on which the checking, evaluation or study takes place? It is virtually self-evident

\footnotetext{
${ }^{5}$ For a stimulating presentation of the importance of institutional independence in the context of judicial independence see the speech of Lord Phillips, the first President of the Supreme Court of the United Kingdom, 2009-2012 [6]. Among the points Lord Phillips makes is the following: "Because it is the executive that exercises the power of the State and because it is the executive, in one form or another, that is the most frequent litigator in the courts, it is from executive pressure or influence that judges require particularly to be protected. And so in this talk I am going to concentrate on the institutional independence of the judiciary".

6 "By the 18 th century, the term "statistics" designated the systematic collection of demographic and economic data by states. For at least two millennia, these data were mainly tabulations of human and material resources that might be taxed or put to military use" $[7,8]$.

${ }^{7}$ Seltzer discusses the matter of the broad mission of official statistics production ("the statistical service") and notes efforts in the 1980 s in the UK and the US to narrow the mission of official statistics production to "a narrower and what appeared to many a more partisan mission... The narrow approach could certainly be said to have characterized the mission of the statistical services of the former USSR and the other command economies of Eastern Europe" [9].
}

that a system of production of official statistics where conflict of interest is inherent in its setup would not maximize trust in the statistics.

To sustainably buttress professional independence, impartiality and objectivity in official statistics and maximize trust in them one would need more than the currently proposed safeguards, which are anyway not being fully implemented and which could be characterized as "patchwork" if they lack the core of institutional independence. There is a need for a fundamental reform, a paradigm shift in the way we approach the production of official statistics, by rendering it a separate branch of government. The paradigm shift would involve changes both in the institutional conditions for independence and in the culture and attitude towards independence, with these objective and subjective elements reinforcing each other over time.

Would this paradigm shift take care of all challenges to professional independence in official statistics? Would there still be instances of external pressures on official statisticians or of self-censorship of these statisticians? Some challenges would certainly remain. External pressures and self-censorship could still take place, as they could in the case of the judiciary, even though it may be set up as an independent, separate branch of government. However, the independence of the new system of official statistics production would be much more robust than any system being part of the executive branch of government or of any other branch of government. This would be reflected in the degree of trust that the new system would command in the broad spectrum of the users of official statistics in modern societies.

\section{Professional independence of official statistics, institutional dependence and safeguards}

\subsection{Independence and dependence: institutional and professional}

In discussing potential changes to the status quo of official statistics production taking place within the executive branch of government - we need to address whether practices and behaviors (i) consistent with and (ii) necessary for the attainment of independence, impartiality and objectivity in the production of official statistics are best served by the status quo or by a system of statistical production as a separate branch of government. In this context, we apply an approach whereby we set out the above optimal practices and be- 
haviors and we ask under which system they are more likely to be (a) carried out and (b) carried out in a sustainable manner.

Annex I presents a list of optimal practices. ${ }^{8}$ The first part of the list provides practices that should be carried out by those outside the statistical perimeter, i.e., users of official statistics such as policy makers, legislators, civil servants/administrators as well as market participants, academic researchers and the general public. The second part of the list provides practices for official statisticians directly involved at any given point in time/stage of statistical production, i.e., those inside the statistical perimeter. It should be noted that administrative data or other upstream data providers are not within the statistical perimeter for the production of the downstream statistics but outside it.

For independence, impartiality and objectivity to be achieved in the production of official statistics, both those outside the statistical perimeter as well as those inside the statistical perimeter must follow the practices and behaviors in the list in Annex I. The question is whether the practices and behaviors enumerated in that list can be more easily (are more likely to be) achieved and sustained when official statistics production is institutionally part the executive branch of government or separate from it.

Our view is that all of the practices listed in Annex I - which are consistent with and necessary for the attainment of professional independence, impartiality and objectivity in the production of official statistics are more easily and more likely to be achieved and sustained with official statistics production being institutionally outside the executive branch of government instead of inside it. In the current approach of official statistics production taking place within the executive there are more risks that external pressures will materialize concerning statistical methods and outcomes, timing and content of statistical releases, and even with regard to statistical confidentiality. Very importantly, there are more risks in this approach that official statisticians will anticipate the above pressures, or just the preferences and sensibilities (actual or perceived) of "political masters" or "colleagues" in the executive, and engage in self-censorship, self-repression and modification of their own behavior in their work as statisticians. And this can take place without necessar-

\footnotetext{
${ }^{8}$ Some of these practices and behaviors have already been codified in various codes of practice and declarations of principles, values and ethics, such as $[4,5]$.
}

ily overt pressure from any specific official or institution within the executive branch of government.

The above risks are mediated and amplified by administrative and resource dependencies of official statistics production on the executive branch of government. Some of the aspects of these dependencies are provided here:

- Hierarchical/authority/accountability relationships with officials in the executive branch of government

- Institutional conflation or affiliation with institutions in the executive branch of government

- Conflation or amalgamation of any of the individual administrative and budgetary functions of the statistics office with those of institutions in the executive branch of government

- Control of human resource issues (e.g., staff hiring, promotion, remuneration, terms and conditions of work), financial resource issues (e.g., access to approved budget funds, distribution of approved budget to expenditure lines, expenditure commitments, financial administration, auditing and settlement of expenditures), and other resource issues (e.g., access to foreign aid) by the executive branch of government ${ }^{9}$

- Physical proximity with/embedding of the statistics office in other institutions

- Control of the selection, appointment, reappointment, remuneration, termination of the incumbency of the head of the statistics office by the executive branch of government

- Officials carrying out non-statistical work/functions along with their statistical ones

- Assignment of parts of statistics office operations (statistical or administrative) to other institutions

These aspects of dependency can exist de jure, provided for in the legal framework, or de facto, if there are lacunae in the legal framework or the legal framework is simply not being implemented.

\subsection{The effectiveness of safeguards}

In a discussion of the above matters one ought to consider the effectiveness of safeguards. Specifically,

\footnotetext{
${ }^{9}$ It is a widely accepted argument in the case of the judiciary that if spending on the judiciary is controlled by the executive, this is considered to undermine the principle of judicial independence because it creates a financial dependence of the judiciary on the executive. Corruption of the judiciary by the state (through budget planning and privileges) is considered more dangerous than private corruption [3].
} 
according to what are considered best practices nowadays, the professional independence of official statistics production is supposed to be secured through safeguards, which under the best of circumstances, would include:

- Provisions in law for the implementation of statistical principles in the national statistical system, including in particular those of professional independence, impartiality and objectivity ${ }^{10}$

- Policy commitments of governments to support confidence in official statistics by maintaining or improving conditions for the implementation of statistical principles ${ }^{11}$

- National level institutions with the mandate to report on the implementation of statistical principles and in particular of professional independence $^{12}$

- Provisions in law for the selection, term in office and termination of incumbency of the head of the statistics office

- Provisions in law for control by the statistics office of human and other resources

- Quality assurance of statistical output by supranational entities

- Review of implementation of statistical principles by supranational entities and processes

Are such safeguards actually in place in most countries around the world? Are usually safeguards actually put in place in an appropriate and strong form? Do the safeguards actually in place apply to official statistical production in the entire national statistical system, i.e., is the full scope of official statistical outputs and are all official statistics producers in the country covered? Unfortunately, the answer to all of the above questions is negative.

If and where such safeguards are in place, do they effectively address the risks of external pressures and self-censorship? More specifically, does the presence of safeguards effectively address the risks on account of the dependencies of official statistics production on the executive? We believe that these safeguards can help somewhat reduce the risks, but definitely not to the point where risks would be reduced if institutional independence of official statistics were to be formally and explicitly recognized.

\footnotetext{
${ }^{10}$ See or example Regulation (EC) No 223/2009 of the European Parliament and of the Council on European Statistics [11], Article 2.

${ }^{11}$ See for example ibid., Article 11.

${ }^{12}$ See for example ibid., Article $5 \mathrm{a}$.
}

As long as institutional independence from the executive branch of government is not formally and explicitly recognized, any patchwork of safeguards will not be fully effective and risks will not be reduced enough. For example, national level institutions with the mandate to report on the implementation of professional independence of official statisticians, as well as international quality assurance processes and peer reviews of implementation of statistical principles can be rendered ineffective if the statisticians in statistical offices are serving political interests projected through the executive branch of government they are part of. The legal provisions for adhering to statistical principles can also be ignored when other approaches prevail those of "loyalty" to "political masters" (which is how some official statisticians refer to policy makers) or of statistics serving the "national interest" as understood by politicians in power. Explicit political commitments to support confidence in statistics can be outright ignored by governments or "managed" with evasive approaches. Furthermore, the best practices legislated for the selection of the head of a statistics office can lead to suboptimal outcomes when there are serious negative cultural and other factors operating against professional independence, impartiality and objectivity in the wider environment in which official statistics production takes place, leading to narrow fields of candidates coupled with serious adverse selection.

In addition, where institutional independence is not in place, the above safeguards cannot adequately and sustainably dislodge incentive structures and psychological conditions conducive to self-censorship and self-repression on the part of at least some official statisticians. Some statisticians would continue to desire to be "part of the team" and be "cooperative", exhibit "loyalty" to "political masters" and seek their approval, and desire the "protection" and "facilitation" of the branch of government they see themselves as part of. In contrast, with institutional independence explicitly in place and thoroughly buttressed such phenomena would be rare.

It should be pointed out that some of the safeguards mentioned above actually constitute necessary conditions for extracting official statistics production from the executive branch of government and supporting its institutional independence. For example, a declaration of the institutional independence of official statistics production would have to be accompanied by provisions in law for control by the statistics office of its human and other resources. Without such provisions, the spirit and implementation of the declaration of institu- 
tional independence would be thoroughly undermined. At the same time, the formal declaration and explicit recognition in law of institutional independence of the production of official statistics would help bring about the appropriate and strong form of safeguards (such as on the control by the statistics office of its resources) and create a very firm basis for the effective implementation of safeguards.

In the context of this discussion, we would also like to address whether a culture and tradition of professional independence in the production of official statistics can be a robust enough safeguard for sustainable professional independence when the production of official statistics is part of the executive? Our view is that it is not. Having a benign culture is fine, but not something to rely on in the long term. Sooner or later challenges will arise that will not be handled as appropriately as when official statistics production is institutionally independent. The history of official statistics in the last 100 years is replete with better and less well known incidents of serious challenges to the professional independence of official statisticians, involving in some instances even countries considered to have overall positive cultural traditions regarding official statistics. ${ }^{13}$ However, we would argue that culture and tradition would become more powerful supporters of the professional independence of official statisticians in a system where separation of official statistics production from other branches of government is provided for in law and expressed in institutions.

Finally, we would argue that while the discussion above has focused on the risks to professional independence, impartiality and objectivity from official statistics being a part of the executive, the risks to another fundamental statistical principle, that of statistical confidentiality, are also greater when statistics production is a part of the executive. There are various instances in the history of statistics in the twentieth century [9] that illustrate this point. There are also some challenging situations that have recently developed in at least a couple of countries (e.g., in Canada [10]) that can be mentioned in support of our argument.

\section{The paradigm shift of institutional independence}

In this section we provide an outline of some elements of the paradigm shift of institutional independence of official statistics production.

\footnotetext{
${ }^{13}$ For some examples see [9].
}

Official statistics production would need to be declared in law as separate from the executive branch as well as other branches of government. Formal declaration in law of such status of institutional independence would be a core element of the change in approach. The law would prohibit any institutional conflation or affiliation of the institution of the statistics office $^{14}$ with institutions in the other branches of government. There would also be explicit provisions in the law against any conflation, amalgamation or subjugation of any individual administrative and budgetary functions of the statistics office with those of institutions in the executive branch or other branch of government. The law would also prohibit staff of the statistics office to simultaneously work in other branches of government.

The law would specify that the executive or other branches of government would not control human resource issues (e.g., staff hiring, promotion, remuneration, terms and conditions of work) as well as financial resource matters (e.g., access to approved budget funds, distribution of approved budget to expenditure lines, expenditure commitments, financial administration, auditing and settlement of expenditures), and other resource issues (e.g., access to foreign aid). The head of the statistics office would have sole responsibility of the administration of the statistics office including the use of its human, financial and other resources, fully observing of course the existing national laws on such matters. This responsibility would go hand-in-hand with law-provided transparency and accountability in the use of resources by the statistics office, along the lines indicated below.

The financial statements of the statistics office would be drawn up by its accounting officer and audited annually by an external auditor. The external auditor's report would be published in the official journal of the government and also conveyed to the executive and legislative branches of government. The statistics office would compile and publish a budgetary and financial management report providing an overview of the implementation of its budget, which would be published. The report would also be submitted to the legislative and the executive branches of government. The statistics office would have an internal audit service that would be independent in carrying out audits,

\footnotetext{
${ }^{14}$ Throughout the paper we use the term "statistics office" to denote any official statistics producing body (national statistical authority) in the national statistical system and not just the national statistics office.
} 
which would cover all of the statistics office's activities and parts. It would have full and unlimited access to all the information needed to carry out its work. The legislative and the executive branches of government would receive reports containing the number and type of internal audits carried out, the recommendations made and the action taken on those recommendations. These reports would also be published.

Physical proximity (cohabitation) and embedding of statistics offices within other branches of government would be prohibited. There would be further specifications in law with a view to minimizing the dependencies of the production of official statistics on other branches of government in the following areas: (i) any remaining hierarchical/authority/accountability relationships with officials in other branches of government; (ii) selection, term in office and termination of incumbency of the head(s) of the statistics office(s) in the country, with selection being carried out by an independent selection committee; (iii) an independent compensation and benefits committee, which would make recommendations to the government about the compensation and benefits of official statistics producers.

There would of course also have to be provisions in law for (i) the implementation of statistical principles in the national statistical system, including in particular those of professional independence, impartiality and objectivity; (ii) policy commitments of governments to support confidence in official statistics by maintaining conditions for the implementation of statistical principles, including for the institutional independence of official statistics production; (iii) national level institutions with the mandate to report on the implementation of institutional independence as well as on other statistical principles.

The law would also specify that official statistics producers would have to have a very attentive and responsive attitude towards the user needs of the executive and of other branches of government. Official statisticians would have to be fully aware of these users' needs through proper arrangements, such as advisory user committees, user conferences, specialized user groups, and periodic and ad hoc consultations with these users. These arrangements would be provided for in law, along with the requirement that all consultations with users are documented and their contents publicized. This kind of transparency would increase the accountability of official statistics producers for being responsive to the needs of users, but also reduce the risks that user requests for "what" statistics are produced get mixed up with conversations about "how" the statistics should be produced and what the final statistical figures should show.

International structures of accountability would continue to be important in a world where official statistical production is extracted from the executive branch of government. They may even be more important under the new paradigm as those resisting the institutional independence of official statistics may invoke unjustifiably in our view - inherently inadequate transparency or accountability when official statistics is not part of another branch of the national government. The law would provide for the possibility of quality assurance of the statistical output as well as for the review of the implementation of statistical principles by supranational entities. Such entities could be broadly modeled for example after Eurostat's review of government finance statistics within the European Union regarding quality assurance, and after the European Statistical System Peer Reviews and the European Statistical Governance Advisory Board regarding the implementation of statistical principles. However, this monitoring and accountability could be further enhanced if there are independent international bodies providing additional monitoring and accountability for national official statistics production. An aspect of these structures of accountability could be, for example, an international institution that monitors the implementation of the United Nations Fundamental Principles of Official Statistics in countries around the world [12].

\section{Benefits and costs regarding the institutional status of official statistics production}

What would be the relative benefits and the costs of retaining the production of official statistics within the executive and of rendering such production an independent branch of government?

The economic and social, as well as political costs that arise from lack of professional independence, impartiality and objectivity and consequent real or perceived problems in the quality of statistics are very large. This is because the resultant official statistics impede the following:

- Operation of the democratic system at national level

- International cooperation and the production of international public goods such as international financial stability and climate change mitigation 
- Efficient operation of markets, their orderly adjustment and economic welfare maximization ${ }^{15}$

- Scientific research and progress

These costs would not be incurred or would be much smaller if official statistics production were extracted from the executive branch of government.

In addition, the costs of effective supervision/checking of official statistics when it is part of the executive, along with the costs of developing alternative sources of information, would be higher than in a system where official statistics production is a separate branch of government. One may add that the costs incurred by other official statistics producers around the world to maintain the trust of users in their own official statistics would be lower when statistics production in any given country $\mathrm{A}$ is institutionally independent, on account of the greater credibility of official statistics of A [12].

Turning to the potential benefits of official statistics production being part of the executive, some commonly proposed ones are the following:

- "Access" of official statisticians to policy/decision makers that official statisticians get by being part of the executive branch, which is thought to provide assurances that the views of official statistics production are heard and statistics are protected from various adverse budgetary, legislative and other policy developments.

- Collegiality and close relations with various parts of the civil service in the executive branch, which are thought to help protect official statistics production from the various adverse developments mentioned above as well as facilitate administrative processing of any kinds of requests of statistics producers.

- Access of official statistics production to resources of the state administration, and in particular its human resources, which can provide support in areas within statistical production, and to the government's administrative data sources, which are important for modern official statistics production.

- Input and feedback for producing statistics relevant to the work of government, which is a major user of official statistics.

\footnotetext{
${ }^{15} \mathrm{In}$ arguing for the independence of the judiciary a similar point is made: state corruption of the judiciary can impede the ability of businesses to optimally facilitate the growth and development of a market economy [3].
}

To the above propositions regarding benefits from official statistics production being part of the executive branch of government we offer the following comments:

- The head of the statistics office does not need to be part of the executive branch of government to have access to policy/decision makers. Such access is possible and can take place by providing for it in the law. Moreover, access is more likely to take place with the appropriate and necessary propriety and respect for statistical independence when the statistical interlocutor is institutionally independent than when she is a subordinate and someone who "reports" in the hierarchy of the executive branch.

- Accommodation of the interests and needs of official statistics producers and protection of official statistics production from adverse legislative, budgetary and other policy developments would be best served with little risk of quid-pro-quo if it was provided for in law (e.g., regarding the role of the statistical producers in the legislative process or regarding multiyear adequate funding for statistical production) and official statistics production was a separate branch of government.

- The closeness and collegiality of civil servants of the executive branch does not offer protection to statistical production from adverse legal/ budgetary developments and administrative friction without also increasing the risks to the statistical perimeter, which undermine independence.

- Appropriate access to expertise and information existing in the executive branch of government does not have to go hand in hand with official statistics being part of the executive. In any event, provision of expertise and information by the executive branch is more likely to increase the risk of the policy making/administrative perspective contaminating the statistical approach when official statistics production is part of the executive branch. Official statistics production should and could have its own expertise in areas where it traditionally needs it and not be dependent on expertise existing in the executive branch.

- Effective access to administrative data sources does not have to be mediated by statistics being part of the executive. Access to administrative data sources is best achieved, and at the same time statistical confidentiality best protected, when access is provided for in law and the statistics office is not part of the executive or other branches of government. 
- It is not necessary for official statistics production to be part of the executive branch of government in order for official statisticians to have a very attentive and responsive attitude towards the needs of this very important user of official statistics. Policy makers and their administrations do not need to have immediate physical and institutional access to official statisticians in order for the latter to be fully aware and attentive to these users' needs. What is necessary instead is proper consultation arrangements provided for in the law. As noted earlier, the risks that user requests for "what" statistics are produced get mixed up with conversations about "how" the statistics should be produced and what outcome the statistics should show are greater when official statistics production is part of the executive branch of government rather than outside it.

In conclusion, from a comparison of the costs and benefits, we believe that it would be clearly more effective and appropriate to extract the production of official statistics from the executive branch of government. Statistics as part of the executive branch of government is a "legacy" institutional setup of another era with many costs/risks and at best ambivalent benefits. There is a need to bring about a paradigm shift and bring official statistics production institutionally out of the 18 th century.

\section{Conclusions}

We have argued that it is necessary that the production of official statistics does not get carried out by one of the branches of government whose performance is being assessed on the basis of these statistics. Given that official statistics are tasked with providing the various branches of government and the public with the information that enables checking on the performance of various parts of government, the optimal setup for statistical production has to avoid the conflict of interest that is inherent in the current approach of official statistics being produced by the executive branch of government. In order to eliminate this conflict of interest and fully and sustainably observe the principle of professional independence of producers of official statistics, there should be institutional independence of the production of such statistics. We have drawn parallels with the (more advanced) efforts to ensure real independence for the judiciary. We have discussed the behaviors and practices consistent with professional independence in official statistics production and we have argued that they are more likely to be followed in a sustained manner when official statistics production is institutionally independent and not subject to the modalities of institutional dependence characterizing the current approach of official statistics as part of the executive branch of government. Proposed safeguards that are supposed to protect the professional independence of official statistics in the current approach - even if implemented, which is questionable - do not minimize the risks to professional independence. Significant risks remain for abuse of dependencies of official statistics production on the executive and the distinct possibility persists for external pressure or selfcensorship of official statisticians, while trust in official statistics is not maximized. There is a need for a paradigm shift and we have provided an outline of some elements of the needed paradigm shift of institutional independence of official statistics production. From a consideration of the relative benefits and costs of retaining the production of official statistics within the executive and of rendering such production an independent branch of government we have found that the costs of retaining official statistics within the executive are large while any benefits are ambivalent at best, and thus we have concluded that it would be appropriate to extract the production of official statistics from the executive.

\section{Acknowledgments}

This paper was presented at the World Statistics Congress ISI 2017, Morocco, 16-22 July, 2017.

\section{References}

[1] Wikipedia, Separation of Powers. Web (retrieved July 6 , 2017). https://en.wikipedia.org/wiki/Separation_of_powers.

[2] Montesquieu C-L, The Spirit of Laws. Available from: https:// socserv2.socsci.mcmaster.ca/econ/ugcm/3113/montesquieu/ spiritoflaws.pdf.

[3] Wikipedia, Judicial Independence. Web (retrieved July 6 , 2017). https://en.wikipedia.org/wiki/Judicial_independence.

[4] European Statistics Code of Practice. Eurostat website. Available from: http://ec.europa.eu/eurostat/documents/3859598/ 5921861/KS-32-11-955-EN.PDF/5fa1ebc6-90bb-43fa-888fdde032471e15.

[5] International Statistical Institute Declaration on Professional Ethics. Available from: https://www.isi-web.org/ index.php/news-from-isi/34-professional-ethics/296-declara tionprofessionalethics-2010uk?showall=1. 
[6] Lord Phillips, Transcript of speech. Available from: https:// www.ucl.ac.uk/constitution-unit/events/judicial-independen ce-events/lord-phillips-transcript.pdf.

[7] Wikipedia, History of Statistics. Web (retrieved July 6, 2017). https://en.wikipedia.org/wiki/History_of_statistics.

[8] Malaguerra C, Mac Donald AL. Statistics as instruments for prosperous, transparent and democratic societies. Statistical Journal of the IAOS 32 (2016).

[9] Seltzer W, Politics and Statistics: Independence, Dependence or Interaction? United Nations, Department of Economic and Social Information and Policy Analysis, Working paper series No. 6. New York. 1994. Available from: https://unstats.un.org/ unsd/statcom/FP-Seltzer.pdf.
[10] Zimonjic P. StatsCan Chief Resigns over Ottawa's Failure to Protect Agency's Independence. $\mathrm{CBC}$ news, $\mathrm{CBC} /$ Radio Canada, 17 September 2016. Available from: http://www.cbc. ca/news/politics/statscan-wayne-smith-resigns-1.3765765.

[11] Regulation (EC) No 223/2009 of the European Parliament and of the Council on European Statistics. Available from: http:// www.nsi.bg/sites/default/files/files/pages/LegalBasis_e/ Consolidated_version_of_amended_Regulation_223_2009_EN. pdf.

[12] Georgiou A. Towards a global system of monitoring the implementation of UN fundamental principles in national official statistics. Statistical Journal of the IAOS 33 (2017). https: //goo.gl/R8NKzU. 


\title{
Annex I
}

Practices and Behaviors Consistent with and Necessary for the Attainment of Independence, Impartiality and Objectivity in the Production of Official Statistics

\author{
Practices and Behaviors of Actors Outside the Statistical Perimeter (Users and Data Providers) \\ Statistical Outcomes, Methodologies and Procedures \\ Do not ask for any statistical outcomes or nonstatistical goals \\ Do not ask for circumventing or "managing" any rules in statistical methodology or procedures \\ Do not introduce non-statistical considerations in any discussion with statisticians \\ Do not ask to "be involved" or "help" in statistical production and decisions \\ Do not ask for access to data of respondents to statistical surveys \\ Statistical Releases \\ Do not ask to see the statistical outcomes early; support completely equal access to all users \\ Do not influence the timing of statistical releases \\ Do not suppress statistical releases \\ Do not change the content of statistical releases \\ Do not ask or agree to clear or process statistical releases \\ Do not preempt the statistical office by publishing statistics or discussing statistics before official publication \\ Do not discuss statistics as if there is no statistical perimeter \\ Statistical versus Political/Administrative \\ Do not mix the political or administrative with the statistical \\ Do not press for new formulations of/changes in statistical methodology or procedures for political purposes \\ Do not involve statisticians in arguing for political choices of statistical methodology or procedures \\ Do not involve statisticians in policy bodies and policy activities \\ Maintain clear lines between administrative and statistical parts of institutions \\ Avoid embedding statistics producers in other types of institutions \\ Do not treat statisticians as another set of civil servants \\ Do not make statistics part of political competition \\ Do not curtail specific statistics for political reasons \\ Independence, Responsibility, Accountability of the Head of the Statistics Office
}

The head of the statistics office should be allowed to have the sole responsibility for deciding on statistical methods, standards and procedures, and on the content and timing of statistical releases

The appointment of the head of the statistics office should be based solely on professional competence

For the selection of the head of the statistics office best international practices should be used: Selection process should be carried out in a transparent and accountable way with impartial selectors, with no consideration of political criteria at any stage of the process

Conditions for the termination of tenure of the head of the statistics office cannot compromise her professional or scientific independence

Resources for Statistical Production

Do not maintain a culture of dependency of statistical production on the political. Provide adequate staff, financial, and computing resources to statistical production

Provide for the necessary autonomy, capacity and flexibility of statistical producers to use the human and financial resources allocated to them

Do not engage in any human, financial or other resource practice vis-à-vis official statistics producers that is or can be interpreted as rewarding or penalizing for specific statistical outcomes

Do not engage in political appointments or press for hiring of specific staff within the statistics office

Do not interfere in human resource issues within the statistics office, including promotion, penalization or termination of staff

Practices and Behaviors Within the Statistical Perimeter

Statistical Outcomes, Methodologies and Procedures

Do not take instructions in the production and dissemination of statistics from anyone outside the statistical perimeter, whether explicitly or implicitly provided

Do not accept any interference in the choices of statistical methods and procedures

Do not try to anticipate the interests of any person or group regarding a statistical outcome

Reject unequivocally any predetermined statistical outcome or limits to the outcome, whether this is generated from outside the statistical perimeter or inside it, or from a personal perspective

Do not take into account any non-statistical consideration in making statistical decisions; pursue objectivity without fear or favor, only selecting and using methods designed to produce the most accurate results

Do not accept to circumvent or "manage" any rules in statistical methodology or procedures

Build and maintain a culture of statistical independence, impartiality and objectivity in the statistical office

Do not accept to use as inputs in statistical production upstream data for which you have any indications they are misreported or simply do not meet the quality standards you have set

Protest to withholding of administrative data from statistical production, and use legal levers as deemed appropriate to get the necessary access 

Voice objection if the production of specific statistics is curtailed for political reasons
Do not provide access to data of respondents (households and private enterprises) to statistical surveys to any authority and do not accept
any institutional arrangement that would make such access feasible

Statistical Releases

Provide all users, without exception, access to statistics at the same time. Do not provide access to the statistical results to anyone outside the statistical perimeter before universal dissemination

If pre-release access cannot be avoided on account of a provision in law, it should be fully publicized in metadata, but also upfront in the statistical release with details provided about exactly who has access to what information and when. Argue for changing the law

Do not accept politicians/policy makers clearing or processing statistical releases

Do not seek the clearance by politicians/policy makers of statistical releases

Statistical releases should be objective and impartial, separate from any political statements and references to policy makers

Do not permit any attempt (from within or without the statistical perimeter) to modulate the content of statistical releases so as to serve any political purposes

Present all findings openly, completely, and in a transparent manner regardless of the outcomes

Do not suppress the presentation of statistics when they challenge a "preferred outcome"

Do not modify the date of release of statistics to serve political or other interests. The only reason for a change in the preannounced release date can be serious reasons for safeguarding the quality of statistics, which have to be substantiated and publicized

In press conferences make statements that are objective and nonpartisan and only on statistics. Do not make or comment on projections

Press conferences of statisticians should be completely separate from those of policy makers. Statisticians should neither coordinate with policy makers their press conferences nor give in any way the appearance of such coordination

Do not get drawn into policy/political commentary and conclusions about statistics when discussing with the press

If there are leaks, measures are taken immediately to prevent it from recurring, including measures vis-à-vis any pre-release access to statistics

\section{Statistical versus Political/Administrative}

An official statistician should not treat herself as another civil servant

Resist the view of the official statistician as another civil servant and explain why

An official statistician should see herself as a producer of a global public good

Do not discuss statistics as if there is no statistical perimeter

Guard against being drawn into arguing political choices of statistical methodology or procedures

Argue in all fora for the formulation of statistical methodology and procedures strictly on the basis of statistical/scientific considerations

Do not accept to be involved in policy/political analysis or other political work. Do not accept requests or instructions for assistance/collaboration that may de facto draw you into being part of policy work

Beware of even giving the appearance of being drafted to prove/support one policy view or another or being engaged in policy advocacy

Do not accept to carry out non-statistical tasks so as not to infringe on statistical principles and influence statistical actions, even if these tasks originate in an appreciation of the competence, independence or neutrality of the statistics office, and may even bring resources and prestige

Participate in an activity with non-statisticians only on the condition that you are allowed to act strictly on a professional/scientific basis and you provide views only on statistical issues

In providing advice or guidance, stay strictly within your area of statistical competence. Do not take positions that could be interpreted as policy ones so as to avoid a mixing of competencies and a loss of reputation of objectivity

Do not accept in general any condition or situation that would not allow you to act in a strictly professional/scientific manner currently or in the future

Independence, Responsibility, Accountability of the Head of the Statistics Office

Take responsibility for ensuring that statistics are developed, produced and disseminated by the statistics office in an independent manner

Take sole responsibility for deciding on the statistical methods, standards and procedures, and on the content and timing of statistical releases Resources for Statistical Production

Do not succumb to or adopt a culture of dependency of statistical production on the political with a view to securing staff, financial, and computing resources for statistical production

Present in public a clear and accurate picture of resources needed (cost) for production according to international standards of the statistical output demanded from the statistics office

Do not engage in and do not accept political appointments of staff in the statistics office

Do not accept officials who are currently working in policy making to work simultaneously in the statistics office

Demand the necessary autonomy, capacity and flexibility to use the human and financial resources allocated to the statistics office

Protest and oppose any human, financial or other resource practice vis-à-vis official statistics producers that is or can be interpreted as rewarding or penalizing for statistical outcomes 